\title{
FDA reform moves through Congress
}

Late in September, the U.S. Senate passed comprehensive legislation to reform the US Food and Drug Administration (FDA; Rockville, MD), and the House of Representatives passed a slightly amended version early in October. The legislation would not only streamline the agency and make it more industry friendly, but also extends funding instituted by the five-year-old Prescription Drug User Fee Act (PDUFA), calls for expanded access to investigational drugs, authorizes the use of outside experts to conduct reviews of certain products, and explicitly encourages FDA and other administration officials to harmonize US regulatory practices with those abroad.

In general, officials in the Clinton administration welcomed efforts by Congress to streamline FDA. However, they raised two specific objections to the reform bills. One concerns review standards for new medical devices and the other revolves around PDUFA provisions. The administration claims the provisions could undercut the bipartisan budget agreement that Congress and the administration reached earlier this year.
Meanwhile, many parts of the Senate bill are receiving a broad welcome in industry. For example, renewal of the PDUFA provisions continues to provide $\$ 600$ million per year through user fees, enabling FDA to retain a larger staff and thereby review product applications more rapidly - shaving 10 to 16 months off reviews, according to industry sources. The Biotechnology Industry Organization (BIO; Washington, DC) and the Pharmaceutical Research and Manufacturers of America (PhRMA; Washington, DC) both enthusiastically welcome reenactment of these provisions.

Other reform measures in the bill would grant seriously ill patients quicker access to experimental medicines and would put drugs for life-threatening illnesses automatically on a fast track. FDA is already following such practices to some extent, but is not required to do so under federal statute.

The new legislation also will lead to changes in what information FDA permits companies to disseminate, making it easier for them to share information from peerreviewed journals about "off-label," secondary uses of approved drugs with clinicians and patients. In turn, FDA will be authorized to insist that companies conduct formal trials evaluating additional uses of their products. (see also "Thalidomide checks might have saved Redux," p. 1238).

Much of the debate over the Senate version of FDA reform legislation has centered on how FDA will review new medical devices, with the bill restricting officials to consider only the manufacturer's labeled use for many types of devices. Critics claim that this restriction dilutes the agency's ability to protect consumers; proponents argue that the agency will have ample authority for reviewing inherently riskier medical devices, but that this reform will streamline reviews for a large class of devices that pose little risk to consumers.

Citing risks to consumers from the medical device reforms and a potential "parade of horribles," Senator Edward Kennedy (DMA) tried unsuccessfully to delay the FDA reform bill. "Nothing in the legislation would undermine the agency's ability to use its authority to keep unsafe or ineffective products off the market," says a representative of the Health Industry Manufacturers Association (HIMA; Washington, DC).

Jeffrey L. Fox

\section{...optimize your PCR in one run!}

\section{The gradient function of the new Mastercycler ${ }^{\circ}$ gradient enables rapid testing of 12 different temperatures in one experiment.}

$\begin{array}{llllllllllllllllll}1 & 2 & 3 & 4 & 5 & 6 & 7 & 8 & 9 & 10 & 11 & 12 & 13 & 14\end{array}$

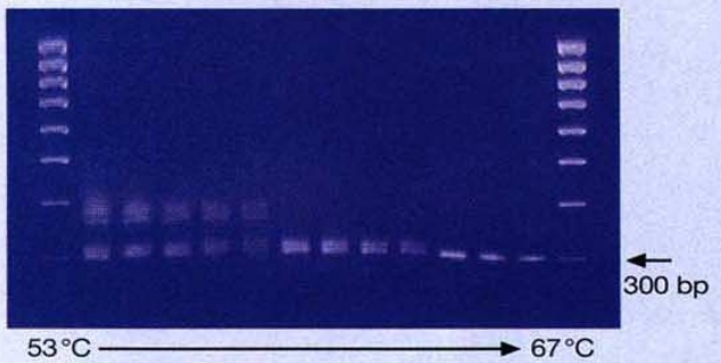

- Fig. 1: Experimental determination of optimal annealing temperature: The calculated primer annealing temperature was $56.5^{\circ} \mathrm{C}$, the actual annealing temperature is $63.5^{\circ} \mathrm{C}$. The ribosomal spacer region of mycoplasms from $\mathrm{H} 9$ cell cultures was amplified.
Using the gradient function of the universal block, a gradient of 53 to $67^{\circ} \mathrm{C}$ was set. The following test parameters were selected: denaturation $10 \mathrm{~s}$, annealing $15 \mathrm{~s}$, elongation $20 \mathrm{~s}$, amount of Taq-polymerase 0.75 units; duration of entire experiment: $<1 \mathrm{~h}$. $\begin{array}{llllllllllllll}1 & 2 & 3 & 4 & 5 & 6 & 7 & 8 & 9 & 10 & 11 & 12 & 13 & 14\end{array}$

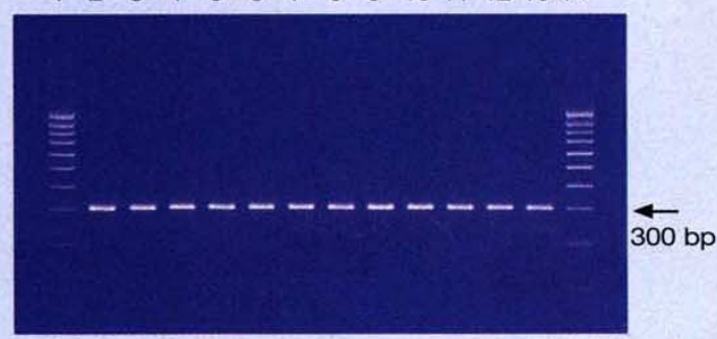

- Fig. 2: Amplification shown in fig. 1 performed under optimized temperature conditions. In this experiment, the universal block was set to a uniform temperature in the annealing phase. The outstanding temperature homogeneity of the block guarantees reproducible PCR results.

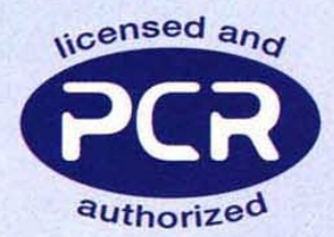

READER INQUIRY NO. 323 